\title{
Qualificação profissional como suporte para implantação do etnoturismo na comunidade indígena Ingarikó (RR)
}

\section{Professional qualification as support for implementation of the indigenous ethno tourism in community Ingarikó (RR, Brazil)}

\section{Elizabete Melo Nogueira, Canrobert Penn Lopes Costa Neto, Georgia Patrícia da Silva}

\begin{abstract}
RESUMO
O presente trabalho apresenta os desdobramentos do Projeto Ecoturismo na Unidade de Conservação do Parque Nacional do Monte Roraima. Em função das demandas dos indígenas sugeriu-se a qualificação profissional como alternativa para o desenvolvimento do etnoturismo na Terra Indígena Raposa Serra do Sol - TIRSS, região Ingarikó, localizada a noroeste do Estado de Roraima, próxima ao Monte Roraima o qual é dividido pelo Brasil, pela República Bolivariana da Venezuela e pela República Cooperativista da Guiana. Sobreposto a TIRSS, região Ingarikó, encontra-se o Parque Nacional do Monte Roraima com uma área de 116.000 hectares. A pesquisa teve caráter qualitativo, descritivo e exploratório. Para a obtenção dos resultados contou-se com visitas "in loco", participação em reuniões e cursos ministrados para a comunidade indígena. Suscita-se que a implantação do etnoturismo pode ser uma estratégia de geração de renda, desde que planejado e que os indígenas tenham participação e gestão do processo.
\end{abstract}

PALAVRAS-CHAVE: Qualificação Profissional; Etnoturismo; Comunidade Indígena Ingarikó.

\begin{abstract}
This study presents the unfolding of Ecotourism Project in the Conservation Unit National Park of Monte Roraima. Due to the demands of indigenous, we suggested a professional qualification as an alternative to the ethno tourism development at the Raposa Serra do Sol area, Ingarikó region, situated at northwest of State Roraima, next to Mount Roraima which is divided by Brazil, the Bolivarian Republic of Venezuela and the Cooperative Republic of Guyana. Superimposed on the Raposa Serra do Sol, Ingarikó region, is located the National Park of Monte Roraima with an area of 116,000 hectares. To obtain the results we counted on "in loco" visits, attending meetings and courses given to the indigenous community. Raises that the deployment of ethno tourism can be a strategy for income generation, since planned, with the indigenous participation and process management.
\end{abstract}

KEYWORDS: Professional Qualification; Ethno Tourism, Indigenous Community Ingarikó. 


\section{Introdução}

Este texto descreve as atividades desenvolvidas e os desdobramentos do Projeto Ecoturismo na Unidade de Conservação do Parque Nacional do Monte Roraima na Terra Indígena Raposa Serra do Sol - TIRSS, na região Ingarikó, e tem como objetivo ressaltar a qualificação profissional como fator condicionante para a implantação do etnoturismo nessa região.

O Parque Nacional do Monte Roraima - PARNA - é uma unidade de conservação - UC integral, incide sobre a TIRSS e foi criado pelo Decreto № 97.887 de 28 de junho de 1989. O objetivo básico desse projeto é a preservação do ecossistema Pacaraima, haja vista sua grande relevância ecológica e necessidade de proteção das espécies da flora, fauna e recursos naturais, oferecendo oportunidades de visitação controlada, educação e pesquisa. Como uma UC, o PARNA, de acordo com Rufino (2004, p. 418) impõe regras para o seu uso, a fim de "impedir a interferência humana direta ou qualquer modificação de seu ambiente", exceto as situações previstas em lei.

A região Ingarikó está localizada no extremo norte do Brasil (figura 1), no município do Uiramutã, estado de Roraima, numa área de sobreposição ao Parque Nacional do Monte Roraima. De acordo com Silveira (2010, p. 161) é um "bem público da união" e está submetido "ao regime jurídico da dupla afetação", em que predominam dois interesses: a preservação do ambiente natural e a "realização dos direitos constitucionais" dos indígenas.

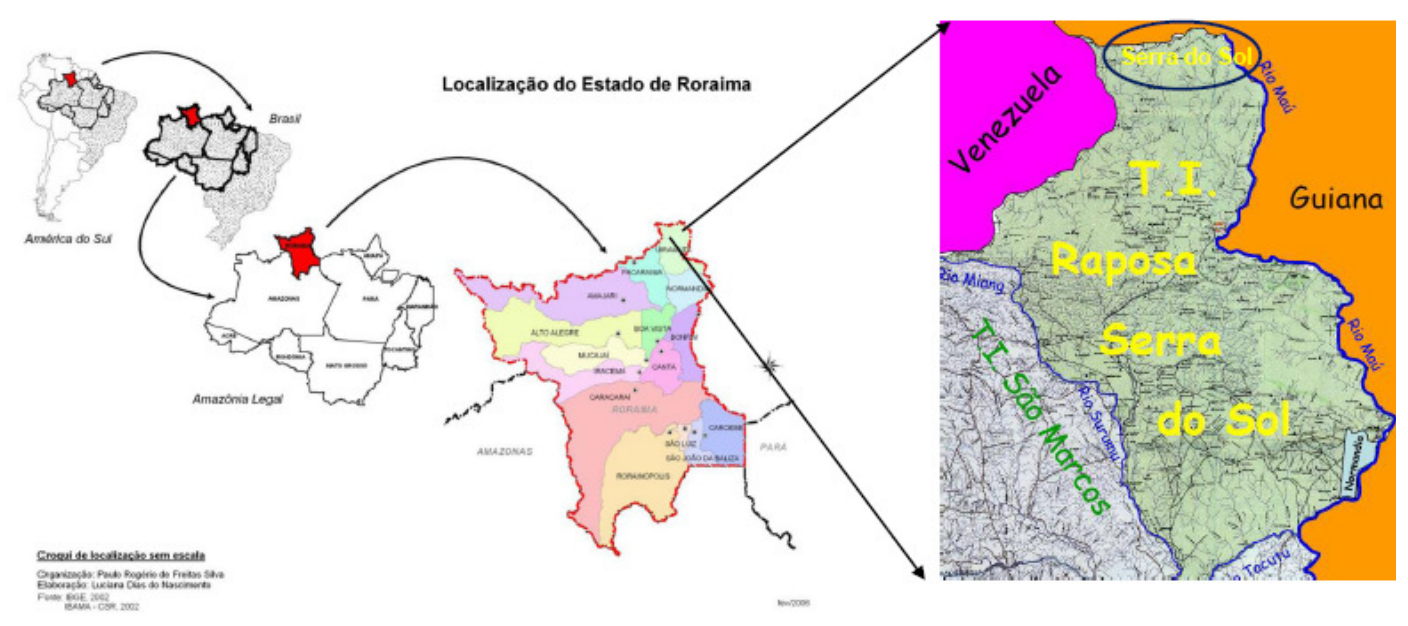

Figura 1: mapas de localização da região Raposa Serra do Sol. Fonte: Freitas (2007), com adaptações apud IBGE/IBAMA (2002).

Figure 1: Location map of the region Raposa Serra do Sol. Source: Freitas (2007), with adaptations cited IBGE/IBAMA (2002).

Em 2010, o Conselho dos Povos Indígenas Ingarikó - COPING, em parceria com o Instituto Federal de Educação, Ciência e Tecnologia de Roraima - IFRR e o Serviço Brasileiro de Assistência à Micro e Pequena Empresa de Roraima - SEBRAE- 
RR celebraram um Convênio que tinha como mote a execução do projeto denominado Ecoturismo na Unidade de Conservação do Parque Nacional do Monte Roraima.

O projeto teve como objetivo estruturar e consolidar a cadeia produtiva do ecoturismo na Unidade de Conservação do Parque Nacional do Monte Roraima como atividade produtiva com foco na preservação ambiental, na inclusão social e no respeito à cultura e tradições do povo da etnia Ingarikó.

Para cumprimento dos objetivos do projeto, o Instituto Federal de RoraimaIFRR designou uma equipe de quatro professores pesquisadores, habilitados para elaborar, organizar material didático e ministrar aulas e demais atividades pedagógicas inerentes aos cursos. O SEBRAE/RR assumiu o apoio logístico disponibilizando um técnico para acompanhar a execução dos cursos, aeronave para o deslocamento dos profissionais, despesas com alimentação, reprodução de material didático e material de consumo. Para facilitar a execução do projeto na área indígena, o COPING auxiliou no apoio à equipe executora, na divulgação, na coordenação, na seleção e na tradução das aulas durante o curso.

No plano de trabalho do projeto estavam previstos os cursos de condutor (técnicas de condução de atrativos, história, geografia e primeiros socorros), educação ambiental, capacitação em hospedagem e acampamento, trilhas interpretativas. Os cursos de História e Geografia faziam parte do curso de Condutor Local e foram ministrados para os indígenas no período de 6 a 11 de setembro de 2010, contou com a participação de índios vindos das aldeias Serra do Sol, Paramaná, Sauparu, Aiwdei, Pipi, Área Única (Sirikokén), Kumaipá, Manalai, Mapaé (Karumanpak Tëi).

Durante o desenvolvimento das ações do plano de trabalho, percebeu-se que os indígenas queriam realmente desenvolver a atividade turística, pois nas assembleias $^{1}$ o turismo era citado como uma alternativa econômica para as comunidades. Na XII Assembleia Geral do Povo Ingarikó e VII Assembleia do Conselho do Povo Indígena Ingarikó - COPING, um dos Tuxauas" ${ }^{2}$, Francisco externou: "temos problemas, pois os jovens vão estudar em Boa Vista e não retornam para a comunidade, talvez o turismo possa ser uma alternativa, porém os povos indígenas deverão ter autonomia e empresas de fora não irão administrar e fazer a gestão".

Percebe-se aqui a constante demanda da liderança dos indígenas da etnia Ingarikó em desenvolver atividades turísticas, visto que já vem acompanhando a prática nas comunidades indígenas de Paraytepuy de Roraima, San Francisco de Yuruaní e Santa Helena de Yuairén, na República Bolivariana da Venezuela. Segundo Silva et al. (2010, p.33) "os indígenas venezuelanos do Parque Nacional Canaima mostram ser capacitados e organizados turisticamente considerando a sua estrutura educacional e social'.

Conforme a demanda para atividade do turismo, as entidades do convênio, notadamente o IFRR, realizaram a análise da situação atual e futura da Região Ingarikó, considerando várias ponderações, inclusive contatando com especialistas na questão indígena para atender aos anseios da comunidade. 
A preocupação dos pesquisadores do IFRR consistiu em entender os reais processos que poderiam ser desencadeados com a efetivação do turismo no local, tendo em vista que a implantação dessa atividade está condicionada a incorporação de alguns hábitos de higiene, o tratamento do lixo produzido, produção de alimentos em maior quantidade, técnicas de recepção, condução e gestão de negócios.

Após uma vivência e mapeamento situacional da comunidade, tomou-se como pressuposto que, para o desenvolvimento do turismo a qualificação profissional é condição fundamental para que as comunidades indígenas possam assumir a gestão do etnoturismo, integrando-as à vida comunitária, de maneira a responderem às suas demandas e dos projetos futuros.

Acredita-se que a qualificação profissional pode atender às particularidades dos povos indígenas e propiciar conhecimentos específicos da atividade turística a partir da valorização do patrimônio material e imaterial, natureza e saberes tradicionais, contribuindo para a reafirmação de suas identidades e sentimentos de pertencimento étnico. Além disso, pode promover a atuação nas próprias comunidades das quais são provenientes, o que por certo, em muito contribuirá para a melhoria de qualidade de vida das populações envolvidas.

É importante esclarecer que neste trabalho o ponto de vista priorizado foi o oIhar dos índios. Para tanto, passa-se a mostrar como pensam os indígenas sobre desenvolvimento do turismo nessa localidade. Com autorização e permissão de entrada na comunidade indígena, teve-se a oportunidade de conversar sobre o turismo e acompanhar as discussões do Conselho dos Povos Indígenas Ingarikó - COPING. Conheceram-se algumas lideranças indígenas, bem como suas opiniões sobre o tema. De 2010 até 2012 realizaram-se três a Serra do Sol visitas resultando em 25 dias na região.

O trabalho tem caráter qualitativo, descritivo e exploratório. Contou-se com a pesquisa "in loco", mediante a participação em reuniões e análise de documentos provenientes de cursos ministrados para a comunidade. Além disso, teve-se a presença em eventos da comunidade, na qual se utilizou a pesquisa participante, proporcionando interação entre os indivíduos e acentuando aspectos importantes, como o registro das falas dos envolvidos.

\section{A experiência com índios Ingarikó}

O Povo Ingarikó pertence à filiação linguística Carib, também autodenominado Kapon. Habita a região Ingarikó Wîi Tîpî, ao norte da TIRSS, extremo norte do Brasil, no município do Uiramutã. Segundo dados do COPING (2011), o povo Kapon representa aproximadamente 1.398 indivíduos, distribuídos em 11 (onze) comunidades, Serra do Sol, Manalai, Mapaé, Kumaipá, Pipi/Paramanak, Sauparú, Área Única, Mura Meru, Awendei, Karumanpak Tëi e Pamak. $\mathrm{O}$ acesso a essas comunidades ocorre por via aérea e entre as comunidades é feito por meio de caminhadas que podem durar de três a quatro dias. 
Esse povo até o início dos anos 80, era apontado como subgrupo Macuxi. No início dos anos 90, os Ingarikó ganharam visibilidade e passaram a atuar entre as demais etnias e a sociedade roraimense. Os Ingarikó se tornaram mais conhecidos devido ao artesanato em palha, a organização de suas escolas e a participação no processo político de demarcação da Terra Indígena Raposa Serra do Sol (TIRSS).

A TIRSS foi homologada (Figuras 2 e 3) por meio do Decreto $s / n$, de 15 de abril de 2005. Após esse ato foi desenvolvido um Plano de Administração da área com dupla afetação pelo PARNA e a TIRSS, região Ingarikó. Este plano prevê a gestão do parque compartilhada entre instituições governamentais, a sociedade civil organizada e os Índios que habitam a região, especificamente, os Ingarikó.

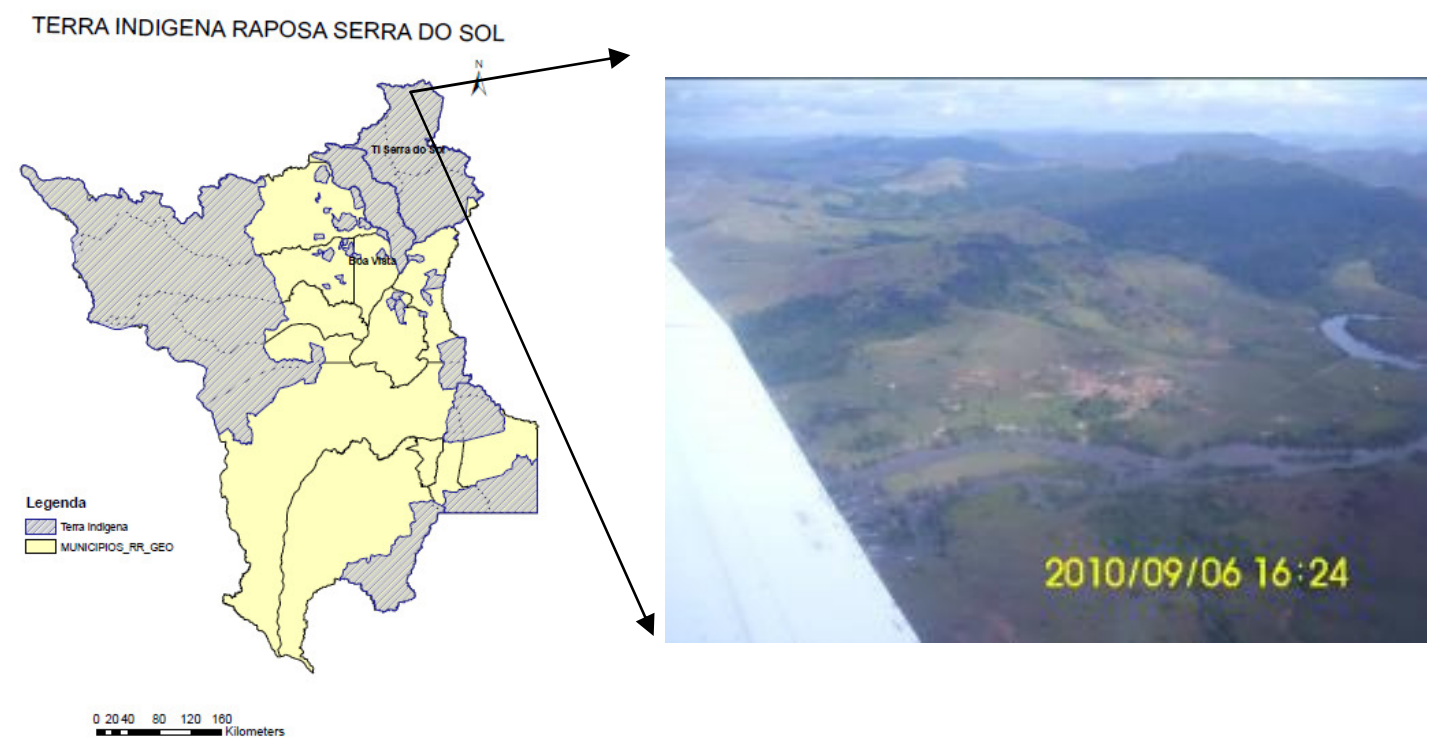

Figuras 2 e 3: mapa de localização da TIRSS, e vista parcial da comunidade Serra do Sol região Ingarikó. Fonte: Mapa e imagem cedidos por Márcia Teixeira Falcão (2012).

Figures 2 and 3: location map TIRSS, and partial views of the community Serra do Sol area Ingarikó. Source: Map and Image ceded by Marcia Teixeira Falcon (2012)

Uma vez que o PARNA foi criado sobrepondo-se a uma porção do território ocupado tradicionalmente pelo povo Ingarikó, as aldeias Karumanpak Tëi e Manalai ficaram localizadas no interior do parque enquanto outras nove estão distribuídas no entorno deste. É importante ressaltar que a criação do PARNA ocorreu quinze dias após ter sido declarada a área indígena Ingarikó pelo grupo interministerial e o trâmite do processo de demarcação da TIRSS estava em andamento.

De acordo com Lauriola (2003, p. 177), os povos Ingarikó "representam o maior grupo indígena" da TIRSS que tradicionalmente habitam "as serras da região nordeste de Roraima, dos dois lados da fronteira", ou seja, território Ingarikó abarca o Brasil e a República Bolivariana da Venezuela, com uma "população de aproximadamente 500 
Qualificação profissional como suporte para implantação do etnoturismo na comunidade indígena Ingarikó (RR)

pessoas, e com a República Cooperativista da Guiana, (ex-Guiana Inglesa), onde o grupo denomina-se Akawaio e registra sua maior população - 7.760 indivíduos".

Lauriola (2003, p.178) chama atenção para o fato de "a Raposa Serra do Sol ter um rico potencial de desenvolvimento, sobre o qual o conflito demarcatório é central. Além dos potenciais minerários já amplamente documentados pelo ISA - Instituto Socioambiental" - cita-se "o potencial de desenvolvimento da indústria do turismo, com suas tipologias, que está diretamente relacionado à implementação do Parque Nacional do Monte Roraima - PNMR".

(Face ao potencial identificado pelo ISA cabe ressaltar que o turismo tem várias modalidades, sendo uma delas o etnoturismo ou turismo indígena. De acordo com Faria (2008, p. 44), "etnoturismo é um tipo de turismo cultural que utiliza como atrativo a identidade e a cultura de um determinado grupo étnico".Para Bahl (2009), o etnoturismo é o turismo étnico, inserido no contexto do turismo cultural, pois os atrativos turísticos estão fincados no contexto do cotidiano de uma comunidade que resguarda suas características culturais.

Em imersão na comunidade indígena, percebeu-se que atualmente a maioria dos alimentos é obtida por meio dos recursos econômicos advindos de programas sociais (bolsa família, aposentadorias, auxílio maternidade), salário de professores e agente de saúde. Em função dessa dinâmica os costumes da comunidade, a produção agrícola, assim como a valorização dos hábitos alimentares estão sendo substituídos por outros, tais como o consumo de bens e produtos industrializados, trazidos de Boa Vista, capital do estado de Roraima, ou do município mais próximo da comunidade, o Uiramutã.

Os próprios índios Ingarikó reconhecem que enfrentam problemas na área da saúde, segurança alimentar e nutricional, já que, atualmente, a produção agrícola é insuficiente para alimentar a população de aproximadamente 1.398 indivíduos. Produzem em pequena quantidade, em virtude da inexistência de assistência técnica na produção de alimentos e criação de animais silvestres. Em face da existência de uma demanda por proteína animal, acarretando escassez de caça para alimentar uma população cada vez mais crescente.

$\mathrm{Na}$ tentativa de minimizar essas dificuldades, os Ingarikó elaboraram alguns projetos que foram encaminhados para instituições públicas, na perspectiva de buscar financiamento para melhoria da agricultura indígena e das roças comunitárias. Porém até o final de 2012 obtiveram resposta para o pleito. Devido a inexistência de investimentos do poder público na área Ingarikó, os jovens têm migrado da comunidade em busca de emprego na cidade de Boa Vista, capital do Estado.

A líder religiosa Gelita ${ }^{3}$ chama atenção das autoridades para as reivindicações feitas em Assembleias anteriores: "Nós estamos enfrentando problemas na área de saúde, não temos água encanada, temos problemas de desnutrição nas nossas crianças, não temos postos de saúde adequados e nem agentes Indígenas de Saúde qualificados". "Não queremos esperar que só o governo faça por nós, o que queremos é 
Nogueira, E.M.; Costa-Neto, C.P.L.; Silva, G.P.

trabalhar junto, povo Ingarikó e Governo". Na fala da líder religiosa são ratificados os problemas enfrentados pela comunidade.

$\mathrm{Na}$ XII assembleia veio à tona a necessidade de assistência técnica rural. A demanda está relacionada à perda das matrizes de gado distribuídas à comunidade por meio de projeto governamental em 1998. Face à inexperiência dos indígenas em manejo, quase todos os animais recebidos foram perdidos.

Nos grupos de trabalho discutiu-se a gestão do PARNA e uma das sugestões apresentada foi: "Enquanto não houver regulamentação do turismo, o COPING, junto com as comunidades e lideranças Ingarikó, deve encaminhar os projetos de turismo e dependerá de uma decisão das lideranças".

Como parte dos resultados alcançados pela VII Assembleia do COPING, foi realizado o curso de capacitação dos condutores de turismo na região Ingarikó, meta prevista para 2012.

A I Feira de Resgate das Sementes Originais, Tradicionalmente Cultivadas, e Fortalecimento da Técnica de Produção Agrícola Indígena Ingarikó teve como tema "Alimentação Saudável é a garantia de educação e saúde de qualidade" e possibilitou aos visitantes conhecer uma mostra de produtos que ainda são cultivados pelos indígenas.

Nas figuras 4 e 5, abaixo, veem-se algumas das produções agrícolas dos índios da região para autossustento.
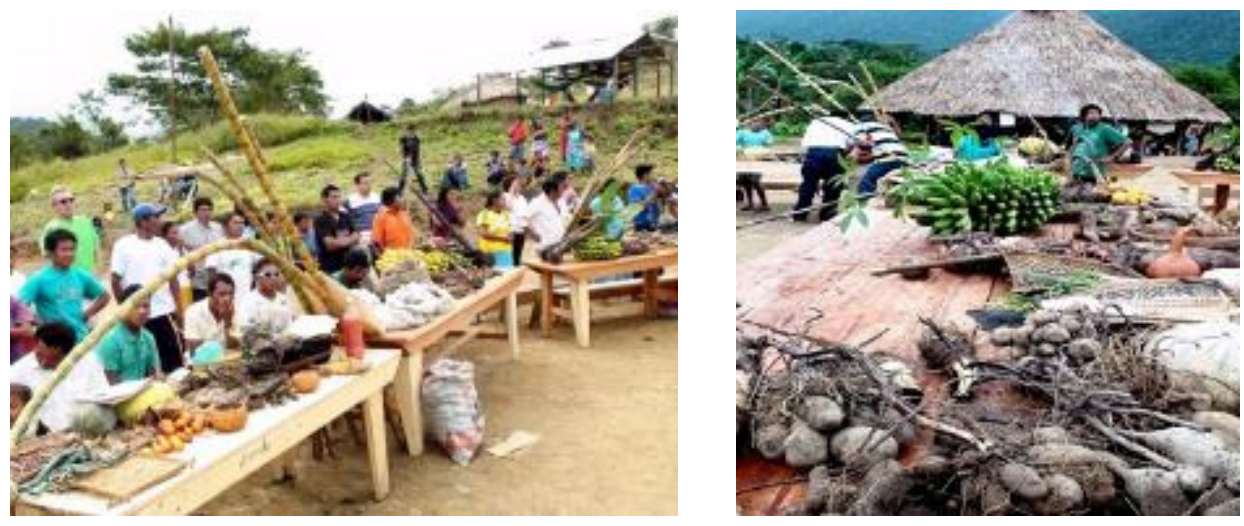

Figuras 4 e 5: mostra de sementes cultivadas na região. Fonte: Fotos de Dilson Ingarikó (2012). Figures 4 and 5: show seeds grown in the region. Source: Photos by Dilson Ingarikó (2012).

Na XII Assembleia Geral do Povo Ingarikó e VII Assembleia do Conselho do Povo Ingarikó, realizadas em setembro de 2011, na comunidade indígena Serra do Sol houve várias deliberações quanto aos procedimentos que deveriam adotar a fim de conseguir benefícios junto ao poder público para as comunidades. Os indígenas também discutiram soluções para resolver os problemas relacionados à educação, à saúde e à segurança alimentar e nutricional. De maneira geral, destacaram-se as se- 
guintes deliberações:

- Viabilização de curso na própria comunidade, pois há grande dificuldade de locomoção pela distância e pelo acesso (somente via avião fretado);

- Disponibilização de cursos profissionalizantes;

- Oferta de cursos profissionalizantes na área indígena pelos parceiros;

- A implantação de cursos de agronomia, turismo, enfermagem, magistério (professor indígena);

- Novas alternativas de renda;

- Incentivo à cultura, como a produção do artesanato para comercialização;

- Incentivo à produção agrícola, agricultura familiar e hortas comunitárias;

- Criação de projetos gerenciados pelos próprios indígenas;

- Elaboração coletiva de projetos nas aldeias, com a participação direta e gestão pela comunidade;

- Desenvolvimento do turismo na região;

- Geração de renda dentro da comunidade.

Nesse sentido, percebe-se que o povo Ingarikó está preocupado com o desenvolvimento de suas terras e por isso buscam programas e projetos alternativos visando à conservação e utilização dos recursos naturais para o seu desenvolvimento. Esta consciência demonstra o interesse coletivo de fortalecer as práticas alternativas, na perspectiva de construir um modelo de desenvolvimento para essas comunidades, valorizando suas práticas culturais.

Ao fazer seu pronunciamento a respeito do atendimento às reivindicações propostas pela comunidade, o lider Dilson Ingaricó ${ }^{4}$ disse que deve "com esse horizonte buscar autonomia na produção, identidade e cultura Ingarikó". Enfatiza ainda "que os projetos devem primar pelo respeito cultural como no caso da alimentação versus cultura".

A religião indígena Coração do Mundo é a fé professada pelo povo Ingarikó, esta é fortalecida pelas apresentações da dança e do canto aleluia durante as cerimônias de agradecimento pelos alimentos, pela boa caça, para abertura de eventos e mesmo no cotidiano da comunidade. Os membros do projeto responsáveis pela eleição do representante do Conselho Consultivo foram recepcionados com canto e dança realizados pelos indígenas, uma forma de dar boas vindas aos visitantes (Figura 6) .

Nos relatos dos indígenas, percebeu-se que algumas mudanças de costumes vêm acarretando também o distanciamento dos indígenas com a natureza. Associados ao crescimento demográfico nas aldeias, na região Ingarikó, ocasionaram diversas alterações no modo de viver, dessas pessoas. Percebeu-se, ainda, a facilidade com que os indígenas identificam e fazem mapeamento dos recursos naturais, inclusive demonstrando a coloração do solo, como são utilizados esses recursos, indicando as variedades agrícolas que podem ser produzidas na localidade. 

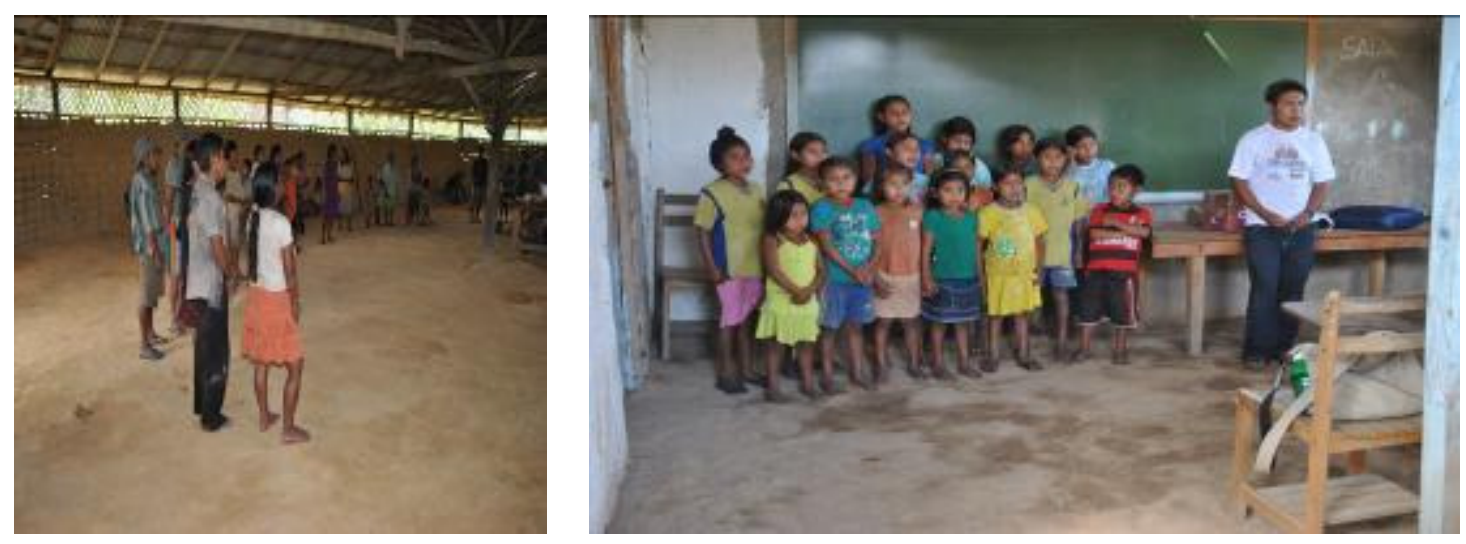

Figura 6: apresentação da dança aleluia e do coral de crianças de Manalai e Mapaé. Fonte: Fotos de Elizabete Melo Nogueira (2012).

Figure 6: presentation of dance hallelujah and chorus of children of the Manalai and Mapaé. Source: Photos of Elizabeth Melo Nogueira (2012).

Nas reuniões, os professores pesquisadores do IFRR ressaltaram que não há soluções prontas, mas há caminhos que podem ser adotados como alternativas viáveis para atender as expectativas dos indígenas e aos preceitos das regiões delimitadas como Parque Nacional. Os indígenas apontaram, que apesar das dificuldades encontradas acreditam que o turismo pode promover mais uma forma de sustento para a comunidade. Mas, na ótica de Silveira (2010, p.138), os Índios Ingarikó "não têm conhecimento detalhado do que representa o turismo, percebendo esta atividade como um objeto estranho, externo à sua cultura e às suas capacidades de lidar com ele".

Em razão dessa visão é que se suscita a qualificação profissional de modo a conhecer Em razão dessa visão é que se suscita a qualificação profissional de modo a conhecer e entender a atividade como uma alternativa socioeconômica na perspectiva de melhorar a qualidade de vida do povo Ingarikó. No sentido de auxiliá-los no processo de encontrar alternativas de menor impacto e de diminuição do deslocamento dos indígenas, descreve-se adiante sobre o etnoturismo e apontam-se alguns cursos e capacitações necessárias para o desenvolvimento desta atividade, atendendo aos anseios dos Ingarikó.

\section{Etnoturismo}

Em virtude de ser uma atividade em crescimento e um setor que envolve vários ramos da economia, o turismo tem uma capacidade geradora de renda e inclusão social.

A terminologia etnoturismo é relativamente nova e as definições acerca do turismo cultural se confundem, uma vez que ecoturismo e turismo ecológico são atividades que estão inseridas nas práticas de turismo que acontecem em áreas ou comuni- 
Qualificação profissional como suporte para implantação do etnoturismo na comunidade indígena Ingarikó (RR)

dades indígenas. De acordo com Santana Talavera (2003), o turismo étnico é uma modalidade do turismo cultural, podendo ser visto como mais uma alternativa para aqueles que procuram 'beleza' no destino e relaxamento proporcionado pelo ambiente 'natural'

Segundo Santana Talavera (2003, p.44), o turismo étnico é "comercializado em termos de costumes 'típicos' e exóticos de povos indígenas" e, entendido como

a viagem com o propósito de observar as expressões culturais e os estilos de vida de povos realmente exóticos [...] As atividades típicas no destino podem incluir visitas a lugares nativos, assistir a danças e cerimônias e a possibilidade de participar de rituais religiosos (MCINTOSH; GOELDNER, apud SANTANA TALAVERA, 2003, p.44).

Apesar da ausência de clareza na concepção de termos e quanto à definição exata de etnoturismo, este é um segmento que atrai um grande número de turistas, devido ao vasto número de atividades que podem ser desenvolvidas. Sabe-se que o turismo em áreas indígenas consiste no aproveitamento da cultura de uma determinada etnia, de modo que todas manifestações culturais de um povo possam servir de atrativo para os visitantes e tem o propósito de preservar a biodiversidade local, com o consentimento da comunidade, visando a estimular o desenvolvimento econômico.

Pelegrini Filho (2000 apud Brito 2009, p.20) aponta que o etnoturismo ou turismo em áreas indígenas relacionam-se aos conceitos de cultura. Por essa perspectiva, estão inclusos no turismo alternativo, que possui um público mais seleto, contrapondo -se ao turismo de massa, enquadrando-se nos conceitos ambientais e de sustentabilidade. O turismo alternativo é assinalado por Mieczkowski (1995) como um conjunto de atividades opostas ao turismo de massa, com formas não associadas ao turismo convencional de larga escala.

Nessa perspectiva, Vieira et al. (2007) enfatiza que os povos indígenas possuem conhecimentos tradicionais milenares que necessitam ser valorizados e reconhecidos. Muñoz (2003) reforça que o sentido étnico desse saber é expresso numa ética do saber cuidar, essa dinâmica se revela numa pedagogia comunitária, sendo reconhecida em saberes compartilhados, que se potencializam por meio do aprendizado indígena.

A principal ideia do etnoturismo é aproveitar o potencial turístico e divulgar a importância e a necessidade de conservação da riqueza existente, tanto em relação ao patrimônio natural quanto ao cultural e tradicional. Para que o etnoturismo seja sustentável em nível ecológico e cultural, é importante que a comunidade informe aos visitantes sobre os costumes locais, as possibilidades de contato, celebrações religiosas, hábitos e expectativas da população quanto ao processo de visitação, inclusive sobre possíveis problemas a serem gerados na relação entre moradores e visitantes. Daí a importância da qualificação profissional e da formação continuada, por intermédio dos saberes indígenas com a implantação do etnoturismo. 
A identificação do que pode ou não ser permitido deve ser acordado pela comunidade para evitar distúrbios sociais e invasão de privacidade dos indígenas. É importante lembrar que algumas festas e cerimônias devem ser resguardadas, quando assim a comunidade desejar, a fim de manter as tradições vivas e autênticas. Também é fundamental que as atividades do etnoturismo sejam praticadas por turistas que tragam consigo o interesse autêntico pela natureza e cultura do local a ser visitado e tenham consciência e disposição para preservar o ambiente.

Para Azevedo (2007), os elementos que fazem parte do etnoturismo: ecoturismo, sustentabilidade, natureza e cultura se inter-relacionam de uma maneira singular na Amazônia. E isso só vem confirmar o potencial do turismo no Estado de Roraima, especialmente na Serra do Sol, onde essa atividade pode ser diversificada, como propõe Wearing e Neil (2001) desde a observação de pássaros, estudo científico, safáris fotográficos, trekking, mergulho, canoagem, caminhada na mata, até a recuperação de ecossistemas danificados.

Entende-se que o povo ingarikó tem uma convivência harmônica com o ambiente natural. Sem destruir os inúmeros recursos que a floresta oferece, acumula de geração em geração conhecimentos e saberes sobre o uso das inúmeras plantas e animais. Seus costumes refletem a convivência em harmonia com a natureza, o que se traduz nas ricas manifestações da cultura amazônica com seu folclore, música, ritos, danças, artesanato e sua culinária.

No entanto, esses conhecimentos e saberes não são reconhecidos pela sociedade envolvente e, com isso, esses sujeitos estão à mercê exclusivamente das políticas compensatórias dos governos federal e estadual. Nesse sentido, Muñoz (2003, p. 286) afirma que

\footnotetext{
o saber indígena implica a memória e uma série sucessiva de atos e de sentido comunitário; se reconhecem em significações éticas e configuram situações harmônicas baseado no respeito, num espaço de identidade e memória de todos. A rede de saberes indígenas não se reconhece em conceitos verbalizados se não em práticas e pela convivência.
}

É necessário que a população como um todo reconheça e valorize a identidade étnica das comunidades indígenas, assim como suas línguas, tradições organizacionais, técnicas de produção, ocupação da terra e recursos naturais, na perspectiva de um convívio pacífico e por meio do intercâmbio cultural que o etnoturismo tem a oferecer.

É necessário, ainda, que os indígenas sejam qualificados profissionalmente e que a atividade seja regulamentada por diretrizes específicas, pois o etnoturismo, assim como outras atividades, deve caminhar dentro das bases legais, a fim de facilitar a fiscalização, garantindo a preservação dos povos, suas culturas e tradições e resguardando o meio ambiente em que vivem, o qual deve ser utilizado de maneira sustentável. 


\section{Qualificação profissional como suporte ao etnoturismo}

Embora tenha-se ressaltado os vários benefícios do etnoturismo, reitera-se que este deve ser planejado de forma a minimizar os impactos negativos. Para a implantação dessa atividade econômica na região Ingarikó, faz-se necessário que os envolvidos sejam qualificados profissionalmente com conhecimentos teóricos, técnicos e operacionais relacionados à produção de bens e serviços na área de turismo.

Como afirma Lopes (2006, p. 85), a qualificação profissional é o processo "por meio do qual se efetiva um encontro estreito entre a aquisição da experiência adquirida e os saberes necessários para fazer frente às situações e condições de trabalho, em geral suscetíveis de transformações, ao longo do tempo". Afinal todo indivíduo carece de uma educação que lhe assegure o domínio operacional de novas tecnologias.

Toma-se a qualificação profissional como a preparação para aprimorar as habilidades dos indivíduos no sentido da especialização em determinadas áreas para executar da melhor forma suas atribuições. A qualificação profissional funciona de forma a complementar a formação na busca por outros tipos de conhecimento, que não os já aprendidos em sala de aula. De acordo com Ramos (2002, p.39), o processo de organização das "relações formais de trabalho" se dá por meio "da existência de práticas educativas que ajudam a legitimar o estatuto do trabalho qualificado".

A partir da Constituição de 1988, Cap. VIII, Art. 231, § 20 "as terras tradicionalmente ocupadas pelos índios destinam-se a sua posse permanente, cabendo-lhes 0 usufruto exclusivo das riquezas do solo, dos rios e dos lagos nelas existentes", assegurando-Ihes o direito de captar recursos financeiros e materiais para gerenciar seus projetos. Os índios puderam vislumbrar a possibilidade de usufruir dos recursos disponíveis em seus territórios, com a finalidade de melhorar a qualidade de vida dos membros que ali habitam, explorando o potencial turístico de áreas isoladas. Algumas experiências já estão sendo desenvolvidas neste sentido.

$\mathrm{Na}$ comunidade indígena Terra Preta, no Baixo Rio Negro, onde a maioria dos moradores é de origem Baré, a língua mais falada é Nheengatu. Segundo Vieira, Souza e Santos (2008, p.363), a comunidade, apesar de não possuir uma agência de turismo receptivo, "tem gerido estratégias para atrair visitantes e turistas". Com a finalidade de manter viva a cultura local da comunidade, uma estratégia utilizada pela escola foi preparar as crianças para realizar apresentações musicais para os turistas. De acordo com Vieira, Souza e Santos (2008, p.361) "a professora ensina cânticos e algumas palavras como estratégia de aprendizagem e revitalização da língua para as crianças", uma vez que estas, apesar de compreenderem o que falam os pais, não são falantes, mas gostam de cantar tanto na escola quanto para os turistas, motivo pelo qual a docente utiliza essa motivação dos alunos para ensinar Nheengatu de forma prazerosa.

O artesanato também figura como outro elemento estratégico de motivação, revitalização e manutenção da cultura. Assim, as crianças aprendem com os seus 
pais e avós a técnica de produção das peças que são vendidas aos turistas e, complementam a renda das famílias. A professora da escola, observando que as crianças, além de auxiliarem na produção da cultura material, também participam na venda do produto, passou a utilizar esse conhecimento do cotidiano para inserir conceitos matemáticos de adição, multiplicação, resolução de problemas.

O respeito e cuidado em relação aos valores socioculturais e o grau de envolvimento com a sociedade envolvente têm sido observados e ressaltados no planejamento dessa modalidade turística, de modo a não permitir a descaracterização da cultura dos povos indígenas.

Nesse contexto, fazem parte do saber indígena diferentes estratégias e atitudes como, por exemplo, saber cuidar (natureza), pois o saber é cotidiano e nessa convivência pratica-se o respeito e reconhecimento dos saberes tradicionais que podem ser utilizados para o etnoturismo. Para tanto, a qualificação profissional para os indígenas, busca, basicamente, capacita-los para desenvolver projetos locais para a melhoria da qualidade de vida da comunidade, mantendo a identidade étnica, os valores culturais e econômicos dos povos.

Dessa maneira, a educação integra ensinar e aprender, um fenômeno visto em qualquer sociedade, responsável pela sua manutenção e perpetuação a partir da passagem, às gerações que se seguem, dos meios culturais necessários à convivência de um membro na sua sociedade. Assim, os saberes indígenas são formas de conhecimentos que se estendem desde o individual ao coletivo, formando um conjunto de conhecimentos conectados aos mitos, ritos e crenças, os quais não possuem conceitos por se basearem em experiências repetitivas dos indivíduos sobre o mundo, de acordo com a experiência dos indivíduos mais velhos. Toledo e Bassols (2008, p.54) reforçam:

\footnotetext{
O conhecimento indígena é holístico porque está intrinsecamente ligado as necessidades práticas de uso e manejo dos ecossistemas locais. O conhecimento indígena está baseado em observações em uma escala geográfica muito restrita, deve fornecer informação detalhada de todo cenário representado pelas paisagens efetivas onde se usam e manejam os recursos naturais. Como consequência, as mentes indígenas não só possui informação detalhada acerca das espécies de plantas, animais, fungos e alguns microorganismos, como também reconhecem tipos de minerais, solos, águas, neve, topografias, vegetação e paisagens.
}

Nesta perspectiva, a qualificação profissional pode ser realizada de várias formas, com o compromisso de repassar algum conhecimento a respeito de como manusear a natureza. Com esta reflexão, deve-se reconhecer que uma educação e uma consciência ambiental adequada constituem os pilares da sustentabilidade ambiental com a legislação e a tecnologia, o que já está assegurado na I Conferência de Educação Escolar Indígena (2009): 


\begin{abstract}
A educação profissional deve considerar as perspectivas de desenvolvimento sustentável e de proteção dos Territórios Indígenas, possibilitando a inserção dos jovens na execução de projetos de acordo com as necessidades e interesses dos povos indígenas. As modalidades de PROEJA e Ensino Médio Integrado devem ser planejadas com a participação de representantes das comunidades interessadas e de professores indígenas, construindo uma proposta que articule conhecimentos e práticas tradicionais com as ciências e tecnologias não-indígenas que possam contribuir para os projetos socioambientais das comunidades (BRASIL, 2009, p.7).
\end{abstract}

Neste contexto, a qualificação profissional objetiva incrementar as competências laborais dos indígenas mediante uma orientação mais específica que a educação geral. Lopes (2006, p.244) destaca que a educação profissional reorienta "a oferta de ensino formação", possibilita "o desenvolvimento de novas oportunidades de emprego, a promoção da qualidade e da inserção profissional" de jovens e adultos para o exercício de profissões de nível fundamental, médio e superior e, por último, atualiza e aprofunda conhecimentos voltados para o mundo do trabalho.

Com base nos pressupostos acima, a suscitação da qualificação profissional para os indígenas da etnia ingarikó tem como foco a possibilidade de estes desempenharem suas atividades produtivas de forma diferenciada, visando a promover ou restabelecer a autossustentação e a inclusão social, de modo que os indígenas possam desenvolver seus saberes na perspectiva de sanar as deficiências limitadoras em relação à sociedade envolvente.

Assim, a qualificação profissional para os indígenas ingarikó é mais um instrumento, como afirma Sá (2006, p.101), de "adoção de novas ferramentas" necessária à melhoria do processo produtivo da comunidade, uma vez que para os indígenas a terra não é vista com valor econômico, mas como espaço produtivo como apontam Toledo e Bassols (2008, p.54):

\begin{abstract}
A terra é venerada e respeitada e sua inalienabilidade se reflete em praticamente todas as cosmovisões indígenas. Os povos indígenas não consideram a terra meramente como um recurso econômico. De acordo com suas cosmovisões, a natureza é a fonte primária da vida, ela alimenta, sustenta e ensina. A natureza é, portanto, não só uma fonte produtiva se não o centro do universo, o núcleo da cultura e a origem da identidade étnica ${ }^{5}$.
\end{abstract}

Dessa maneira, a qualificação profissional para os indígenas, de maneira geral, pode representar não só a manutenção dos seus valores ambientais de acordo com suas cosmovisões, mas a possibilidade de os grupos consumirem os recursos naturais na perspectiva da sustentabilidade da comunidade local. Segundo Toledo e Bassols (2008, p.54), na cosmovisão indígena cada ato de apropriação da natureza tem que ser negociado com todas as coisas existentes (vivas e não vivas) mediante diferentes mecanismos como rituais agrícolas e diversos atos chamânicos (intercâmbio simbólico). 


\section{Conclusões}

Sem dúvida, no que concerne à consecução de melhores padrões de vida e justiça social, o trabalho e a educação são esferas centrais das sociedades do século XXI. A partir desse contexto, o trabalho realizado na comunidade indígena Serra do Sol levou os professores pesquisadores a refletirem sobre a compreensão que o povo Ingarikó tem sobre o turismo, visando à implementação de uma atividade econômica, como geradora de renda, sugerindo a prévia qualificação profissional para o desempenho da atividade.

Entende-se o que saber adquirido durante toda a história da humanidade está submetido ao contexto geográfico, cultural e ecológico de forma intrínseca implica na formação do ser humano. Leff (2003) considera que o saber ambiental pode transformar-se em uma estratégia da apropriação de práticas para adquirir novos saberes, melhorando a qualidade de vida da comunidade.

Nesse sentido, uma formação específica e particularizada pode provocar alteração qualitativa na compreensão da prática social e criar maiores possibilidades de intervenção na realidade. Essa é a contribuição da qualificação profissional no nível de atendimento da adaptação das comunidades indígenas em responder aos seus interesses e a consequente manutenção do seu patrimônio cultural com a prática do etnoturismo.

O desenvolvimento do etnoturismo junto ao povo Ingarikó deve ser planejado, de modo a estimular, qualificar e conscientizar a população sobre os recursos existentes e a capacidade de recepção visando maximizar os aspectos positivos e minimizar os negativos dessa atividade econômica, na perspectiva de gerar renda para as comunidades.

A qualificação profissional torna-se fator fundamental para o desenvolvimento do etnoturismo, quando associada ao real atendimento das necessidades dos indivíduos para o desempenho de uma atividade profissional, considerando as particularidades do viver e olhar indígena.

No caso dos Ingarikó, podem ser oferecidos cursos nas áreas de turismo, enfermagem, assistência técnica adaptada, saneamento ambiental, primeiros socorros, oficina de capacitação e prática de cultivo, manejo dos recursos naturais, respeitando os saberes indígenas e suas técnicas tradicionais de produção, na perspectiva da implantação do etnoturismo com impacto mínimo.

Enfim, o papel das Instituições de Ensino Tecnológico é preponderante para a criação de alternativas que promovam o desenvolvimento regional e sua relevância torna-se maior quando inserida numa reserva indígena. Pensando assim, o IFRR oferece cursos de qualificação profissional na modalidade formação inicial e continuada FIC, técnicos e tecnológicos, além de promover cursos de extensão em diversas áreas, podendo estender para as comunidades indígenas na região Ingarikó. 
Qualificação profissional como suporte para implantação do etnoturismo na comunidade indígena Ingarikó (RR)

\section{Referências bibliográficas}

AZEVEDO, L.L. Ecoturismo Indígena. Quito: Abya-Yala, 2007.

BRASIL. I Conferência Nacional de Educação Escolar Indígena, Luziânia, Distrito Federal: 16 a 20 de novembro de 2009.

BAHL, M. Dimensão Cultural do Turismo Étnico. In: PANOSSO-NETO, A.; ANSARAH, M. Segmentação do Mercado Turístico: estudos, produtos e perspectivas. Barueri, São Paulo: Manole, 2009.

BRITO, T.M. Turismo e povos indígenas. Anuário de Produção Acadêmica Docente. Vol III, $N^{\circ} 4$, ano 2009. Anhanguera Educacional S.A. Publicação 19 de março de 2010.

CRUZ, M.O.S. Fonologia e Gramática Ingarikó - Kapon Brasil. Amsterdam: Vrije Universiteit Amsterdam (Tese de Doutorado), 2005.

FARIA, I.F. Ecoturismo Indígena: Território, Sustentabilidade, Multiculturalismo princípios para a autonomia. Tese de doutorado. São Paulo: Universidade de São Paulo, 2008.

LAURIOLA, V. Ecologia Global contra Diversidade Cultural? Conservação da Natureza e Povos Indígenas no Brasil. O Monte Roraima entre Parque Nacional e Terra Indígena Raposa-Serra do Sol. Ambiente \& Sociedade - Vol. V - no 2 - ago./dez. 2002 Vol. VI - no 1 - jan./jul. 2003.

LEFF, E. (Coord). A Complexidade Ambiental. São Paulo: Cortez, 2003.

LOPES, R.R. Concepções Científicas e Pessoais sobre a Educação/Formação Profissional: Contributos para a elaboração de um modelo teórico. Tese de doutorado. Braga: Universidade do Minho, 2006.

MARTINS, I. R. S.; COUTINHO, H.R.M. Turismo em áreas indígenas. Revista Eletrônica Aboré, Manaus: Publicação da Escola Superior de Artes e Turismo, Edição 03/2007.

MIECZKOWSKI, Z. Environmental issues of tourism and recreation. Lantarn, Maryland: University Press of America, Inc, 1995.

MUÑOZ, M.G. Saber Indígena e meio ambiente: experiência de aprendizagem comunitária. In: LEFF, E. (Coord). A Complexidade Ambiental. São Paulo: Cortez, 2003.

RUFINO, M.P. O Fio da Meada. In: RICARDO, F. (Org.). Terras Indígenas \& Unidades de Conservação da natureza: $O$ desafio das sobreposições organização. São Paulo: Instituto Socioambiental, 2004.

SANTANA TALAVERA, A. Turismo cultural, culturas turísticas. Horizontes Antropológicos, Porto Alegre, ano 9, n.19, p.31-58, out. 2003. 
SILVA, R.D.M.; CRUZ, J.; COSTA, L.A. Parque Nacional Canaima: A identidade socioambiental e turística dos povos indígenas do Monte Roraima. Revista Eletrônica Patrimônio: Lazer \& Turismo - ISSN 1806-700X, v.76, n. 9, jan.-fev.-mar./2010, p.17 -35. Disponível www.unisantos.br/pos/revistapatrimonio - acesso em 01.03.2012.

SILVEIRA, E.D. Meio Ambiente, terras indígenas e defesa nacional: direitos fundamentais em tensão nas fronteiras da Amazônia brasileira. Curitiba: Juruá, 2010.

TOLEDO, V.M.; BASSOLS, N.B. La Memoria Biocultural: La importancia ecológica de las sabidurías tradicionales. Barcelona: Icaria editorial, 2008.

SÁ, A.E. Certificação de competências para o turismo: Uma do seguimento de bares e restaurantes de Salvador - BA, UFB: Escola de Administração, Dissertação de Mestrado, 2006, $160 \mathrm{p}$.

VIEIRA, F.C.B.; SANTOS, A.V.; MARREIR, T.L.C. Saberes indígenas: educação ambiental com os povos indígenas da comunidade Terra Preta do Baixo Rio Negro no Estado do Amazonas. Fórum Ambiental da Alta Paulista. Anais... vol III, 2007. (1CDROOM).

VIEIRA, F.C.B.; PIZA, A.P.; SANTOS, A.V. Saberes indígenas, educação ambiental e turismo étnico com os povos indígenas da comunidade terra preta no Baixo $\mathrm{Rio} \mathrm{Ne}$ gro. Anais do I Congresso de Ecoturismo da Amazônia. Universidade Federal do Amazonas. Departamento de Geografia. Manaus: 24 a 28 de novembro de 2008. pp $476-489$.

VIEIRA, F.C.B.; SOUZA, E.R.V.; SANTOS, A.V. Ecoturismo e Interculturalidade na Comunidade Indígena Terra Preta, no Baixo Rio Negro: uma proposta de inclusão social. Anais do I Congresso de Ecoturismo da Amazônia. Universidade Federal do Amazonas. Departamento de Geografia. Manaus: 24 a 28 de novembro de 2008. pp. $348-366$.

WEARING, S.; NEIL. Ecoturismo-Impacto, Tendencias y Posibilidades. Madrid: Editorial Síntesis, 1999.

\section{Notas:}

${ }^{1}$ Reunião realizada anualmente na aldeia Serra do Sol a qual reúne o povo Ingarikó, representantes de instituições públicas e da sociedade civil organizada, (convidados), para discutir e deliberar ações para o ano seguinte. Concomitante a assembleia geral ocorre a assembleia do COPING com a finalidade de avaliar as ações desenvolvidas pelo conselho durante $o$ ano e a cada dois anos eleger o presidente da entidade.

${ }^{2}$ O Tuxaua é um líder político com boa oratória e respeitável caçador, cabe a ele representar o povo em eventos internos e externos, organizar as tarefas comunitárias e manter a ordem na aldeia. 
${ }^{3}$ Senhora idosa respeitada na comunidade por ser detentora de conhecimentos sobre as tradições religiosas da comunidade e durante os eventos é responsável pelas orações e ritos indígenas.

${ }^{4}$ Foi o primeiro presidente do COPING, representou o povo Ingarikó como vereador pelo município do Uiramutã, no Estado de Roraima, atualmente é professor na aldeia Manalai e assessor do COPING.

${ }^{5}$ Tradução própria dos autores.

Elizabete Melo Nogueira: Instituto Federal de Educação, Ciência e Tecnologia de Roraima, Boa Vista, RR, Brasil.

Email: betemnogueira@gmail.com

Link para o currículo Lattes: http://lattes.cnpq.br/7571793745280814

Canrobert Penn Lopes Costa Neto: Universidade Federal Rural do Rio de Janeiro, Rio de Janeiro, RJ, Brasil.

Email: canrobertp@uol.com.br

Link para o currículo Lattes: http://lattes.cnpq.br/4801851220092783

Georgia Patrícia da Silva: Universidade Federal de Roraima, Boa Vista, RR, Brasil. Email: geoufpe@yahoo.com.br

Link para o currículo Lattes: http://lattes.cnpq.br/8762583706265854

Data de submissão: 31 de maio de 2012

Data de recebimento de correções: 21 de março de 2013

Data do aceite: 21 de março de 2013

Avaliado anonimamente 